\title{
There might be blood: a scoping review on women's responses to contraceptive- induced menstrual bleeding changes
}

\author{
Chelsea B. Polis ${ }^{*} \mathbb{D}$, Rubina Hussain and Amanda Berry
}

\begin{abstract}
Introduction: Concern about side effects and health issues are common reasons for contraceptive non-use or discontinuation. Contraceptive-induced menstrual bleeding changes (CIMBCs) are linked to these concerns. Research on women's responses to CIMBCs has not been mapped or summarized in a systematic scoping review.

Methods: We conducted a systematic scoping review of data on women's responses to CIMBCs in peer-reviewed, English-language publications in the last 15 years. Investigator dyads abstracted information from relevant studies on pre-specified and emergent themes using a standardized form. We held an expert consultation to obtain critical input. We provide recommendations for researchers, contraceptive counselors, and product developers.

Results: We identified 100 relevant studies. All world regions were represented (except Antarctica), including Africa (11\%), the Americas (32\%), Asia (7\%), Europe (20\%), and Oceania (6\%). We summarize findings pertinent to five thematic areas: women's responses to contraceptive-induced non-standard bleeding patterns; CIMBCs influence on non-use, dissatisfaction or discontinuation; conceptual linkages between CIMBCs and health; women's responses to menstrual suppression; and other emergent themes. Women's preferences for non-monthly bleeding patterns ranged widely, though amenorrhea appears most acceptable in the Americas and Europe. Multiple studies reported CIMBCs as top reasons for contraceptive dissatisfaction and discontinuation; others suggested disruption of regular bleeding patterns was associated with non-use. CIMBCs in some contexts were perceived as linked with a wide range of health concerns; e.g., some women perceived amenorrhea to cause a buildup of "dirty" or "blocked" blood, in turn perceived as causing blood clots, fibroids, emotional disturbances, weight gain, infertility, or death. Multiple studies addressed how CIMBCs (or menstruation) impacted daily activities, including participation in domestic, work, school, sports, or religious life; sexual or emotional relationships; and other domains.
\end{abstract}

Conclusions: Substantial variability exists around how women respond to CIMBCs; these responses are shaped by individual and social influences. Despite variation in responses across contexts and sub-populations, CIMBCs can impact multiple aspects of women's lives. Women's responses to CIMBCs should be recognized as a key issue in contraceptive research, counseling, and product development, but may be underappreciated, despite likely - and potentially substantial - impacts on contraceptive discontinuation and unmet need for modern contraception.

Keywords: Contraception, Menstruation, Menstrual bleeding changes, Contraceptive non-use and discontinuation, Side effects, Health concerns, Amenorrhea

\footnotetext{
* Correspondence: cpolis@guttmacher.org

Guttmacher Institute, 125 Maiden Lane, 7th Floor, New York, NY 10038, USA
}

(c) The Author(s). 2018 Open Access This article is distributed under the terms of the Creative Commons Attribution 4.0 International License (http://creativecommons.org/licenses/by/4.0/), which permits unrestricted use, distribution, and reproduction in any medium, provided you give appropriate credit to the original author(s) and the source, provide a link to the Creative Commons license, and indicate if changes were made. The Creative Commons Public Domain Dedication waiver (http://creativecommons.org/publicdomain/zero/1.0/) applies to the data made available in this article, unless otherwise stated. 


\section{Plain English summary}

Some contraceptive methods cause changes in women's menstrual bleeding patterns. For example, a woman's period may become lighter or heavier, longer or shorter, less regular, or may disappear altogether. Concerns about side effects and health issues - including those related to changes to menstrual bleeding patterns - may limit use of contraceptive methods. However, the research on how women respond to contraceptive-induced menstrual bleeding changes (CIMBCs) has not been summarized in a systematic scoping review. We collected and summarized the body of evidence on women's responses to CIMBCs in a standardized manner. We identified 100 studies from around the world relevant to this issue. We summarized what studies found regarding how women respond when contraceptive methods stop their periods or cause other non-standard bleeding patterns, and the extent to which CIMBCs make women unhappy with their method of contraception, or stop their method of contraception, or not use any method of contraception. We also summarized what the evidence suggests regarding how women think about CIMBCs in terms of their own health, as well as other themes that emerged from our review of studies. While women across countries and populations respond differently to different CIMBCs, due to individual and social influences, it is clear that CIMBCs impact many areas of women's lives. It is important that researchers, medical providers, and contraceptive product developers recognize this as an important issue, and we offer recommendations on how to do so.

\section{Background}

About 99 million unintended pregnancies occur annually, the majority of which could be prevented through use of modern contraception [1, 2]. Concerns about side effects and health issues are common reasons for non-use or discontinuation of contraception among women who do not desire pregnancy [3-5]. Among married women with an unmet need for contraception in 52 developing countries, $7-53 \%$ reported not using a method due to these concerns [3]. Some smaller (often qualitative) studies report on women's experiences with or fears about side effects or health concerns in relation to various contraceptive methods, but few large or nationally-representative studies specifically investigate these issues in detail [6]. Some large-scale surveys (e.g., PMA2020 and Demographic and Health Surveys (DHS)) ask about reasons for contraceptive non-use and discontinuation, and include health concerns, fear of side effects, and interference with bodily processes as broad response categories, but neither survey asks which specific side effects or health concerns led to non-use or discontinuation $[7,8]$. Furthermore, other broad response categories, such as self or partner opposition to contraceptive use, inconvenience of use, or other reasons, may be intertwined with health or side effect-related concerns. Therefore, it is difficult to estimate the prevalence or impact of these concerns, or to disentangle which issues are of greatest concern to women or couples, particularly on a national scale.

Furthermore, while certain contraceptive side effects are clinically documented, various contraceptive-induced bodily processes may be interpreted variably by different individuals. Perceptions of contraceptive-related side effects may be rooted in personal experience, knowledge of others' experiences, or misinformation [9, 10]. While discordance between documented and perceived side effects is acknowledged in the literature [11, 12], both experienced and perceived side effects can be highly influential in contraceptive decision-making processes $[10,13]$. Furthermore, cultural norms and values may shape tolerance (or lack thereof) and fears around various side effects.

Hormonal contraceptive methods and IUDs may induce changes in menstrual bleeding patterns [14-16], which can impact willingness to try or continue using these methods, or method satisfaction [6, 17-23]. Contraceptive-induced menstrual bleeding changes (CIMBCs) may include bleeding patterns which are predictable but diverge from a "typical" menstrual pattern (such as amenorrhea, commonly induced by methods such as progestin-only injectables, or heavy, prolonged bleeding often experienced by copper IUD users [24, 25]), or may cause unpredictable bleeding patterns. While menstrual bleeding can be measured in straightforward clinical categories, there may be large ranges defined around normal menstruation [26, 27] and these clinical definitions may not be in line with women's perceptions of normal bleeding. Furthermore, women may experience CIMBCs they consider abnormal or unacceptable, but may still clinically fall within the range of normal.

In addition to inconvenience (for unpredictable bleeding patterns in particular), and the menstrual hygiene management costs of many bleeding patterns, some individuals may perceive changes to bleeding patterns as being tied to overall notions about their health $[23,28,29]$ or to physical or mental health issues $[6,9,10,12$, $13,20,23,29]$. For example, some women fear that injectable-induced amenorrhea leads to permanent infertility, which is not supported in the literature [30]. Counseling may not always be comprehensive enough to adequately prepare women to fully understand, anticipate, or manage CIMBCs [31]. Though difficult to precisely quantify (owing in part to lack of sufficiently specific nationally representative data, as described above), some evidence suggests that CIMBCs are a central aspect of what women mean when they report 
"side effects" or "health concerns" [32-35], and may be an important reason for non-use or discontinuation. However, the importance of CIMBCs may be underappreciated in the reproductive health field as a key contributor to issues such as unmet need for modern contraception.

In sum, side effects constitute a major reason for contraceptive non-use and discontinuation, and CIMBCs are linked, in both real and perceived ways, with a range of concerns. Differences exist between what bleeding patterns a woman prefers (including the potential for no bleeding changes) and what she is willing to tolerate in exchange for the benefits of the contraceptive options available to her [36]. Understanding women's responses (including attitudes and behaviors) to experienced or anticipated CIMBCs has significant implications for current contraceptive use patterns and for the development of future products, including contraceptives and contraceptive-containing multipurpose prevention technologies (MPTs), which are products in development that aim to deliver varied combinations of contraception and prevention from HIV and other STIs. However, to our knowledge, no recent systematic scoping reviews have examined the extent and range of research on this topic. Thus, we conducted a scoping review to gather and synthesize data on women's responses to CIMBCs and to provide recommendations for providers, researchers, and product developers.

\section{Methods}

\section{Methodological approach}

Scoping reviews are defined as "a form of knowledge synthesis that addresses an exploratory research question aimed at mapping key concepts, types of evidence, and gaps in research related to a defined area or field by systematically searching, selecting, and synthesizing existing knowledge" [37]. Whereas systematic reviews typically focus on a well-defined question of interest (for which appropriate study designs can be identified in advance), scoping reviews are suitable for broader areas of inquiry, for which multiple study designs may be relevant [38]. Women's responses to anticipated or experienced CIMBCs have been assessed in clinical trials, surveys, qualitative studies, and other designs. We aimed to systematically search the literature for relevant content, to organize this information by summarizing the research questions addressed and articulating key themes, and to identify gaps in the existing literature. While we refer to countries in which studies were conducted, most studies were not nationally representative, so findings are not necessarily nationally generalizable.

\section{Search strategy}

We sought to identify peer-reviewed, English-language publications focused on women's responses to CIMBCs among women of reproductive age in any country, published in peer-reviewed journals within the last 15 years (since norms may change over time) [39]. We searched PubMed using Medical Subject Headings (MeSH terms) as follows: ("Menstruation/psychology"[MeSH Terms] OR ("Contraceptive Agents, Female"[MeSH Terms] AND ("menstruation" [MeSH Terms] OR "Menstruation Disturbances"[MeSH Terms] OR "Metrorrhagia" [MeSH Terms]))) AND ((“2002/01/01”[PDAT]: “2017/03/14”[PDAT]) AND "humans"[MeSH Terms] AND English[lang] AND "female" [MeSH Terms]). We also reviewed reference lists of included studies and consulted with topical experts to identify any additional uncaptured studies. We did not search the grey literature.

\section{Inclusion criteria}

To maximize comprehensiveness and feasibility, while minimizing inclusion of irrelevant or minimally informative studies, we required that included studies made reference to examining women's responses to CIMBCs in the title and/or abstract. We excluded studies examining CIMBCs without assessing women's responses to those changes, and those addressing several other narrow topical areas, including:

- Studies that did not explicitly examine women's responses with respect to CIMBCs (e.g., studies on attitudes, cultural beliefs, or practices related to menstruation; age of menarche; impacts of factors such as stress on menstrual patterns; menstrual hygiene management; menstrual synchrony; etc.),

- Studies addressing specific menstrual issues, or intersections of menstruation with specific medical issues (e.g., dysmenorrhea, pre-menstrual syndrome, oral contraceptive-induced menstrual migraine, various psychological conditions, etc.) or constructs (e.g., menstruation and body image),

- Studies conducted within highly specific sub-populations (e.g., women in the military, women with intellectual disabilities), or studies pertinent to methods of contraception that are not typically used as ongoing methods (e.g., emergency contraception),

- Clinical guidance or reviews, or counseling/prescribing habits of physicians (e.g., as it relates to medically induced amenorrhea).

\section{Study screening and data abstraction}

One author (CBP) conducted the initial title/abstract screening using Covidence (advancing abstracts to full-text review in the event of uncertainty) [40], and two investigators (dyads of $\mathrm{CBP}, \mathrm{RH}$, and/or $\mathrm{AB}$ ) read remaining full texts to determine inclusion and abstract data. We developed an abstraction form and pilot tested it on multiple studies to refine it. We collected information 
about the study setting, population, and methodology, including whether it assessed a particular contraceptive method or was non-specific. As scoping reviews generally do not assess study quality [41], these details were minimal. In addition to examining the geographic distribution of identified studies, we extracted information about four key questions (1-4 below), and additional pertinent themes that we mutually identified as emerging from the literature:

1. Women's responses related to contraceptive-induced amenorrhea or other non-standard bleeding frequencies

2. CIMBCs as a reason for non-use, discontinuation, or dissatisfaction

3. Conceptual linkages between CIMBCs and health risks or side effects

4. Use of contraception for deliberate menstrual suppression

5. Other emergent themes

Since bleeding changes occurring from menstrual suppression are deliberately induced, rather than incidental to use of the method, we mention these findings only briefly, but incorporate them where relevant to other themes. Since we excluded studies on highly specific sub-populations, our findings regarding attitudes toward menstrual suppression are not representative of specific subpopulations (e.g., women in the military, women with intellectual disabilities) that may have significantly different attitudes toward menstrual suppression.

\section{Expert consultation}

To enhance the utility and rigor of our review [37, 38, 42], we discussed our preliminary findings in a consultation with five experts on contraceptive acceptability, clinical or social research on CIMBCs, clinical contraceptive provision, and contraceptive and/or MPT product development. We obtained feedback on our overall approach, our literature search methods, presentation of results, and how to make the paper most useful for providers, researchers, and product developers.

\section{Results}

\section{Overview of included studies}

Of 1164 references identified, 100 were considered appropriate for inclusion (Fig. 1). All geographic world regions were represented (except Antarctica), including studies in Africa (11\%), the Americas (32\%), Asia (7\%), Europe (20\%), and Oceania (6\%) (Table 1). The remaining studies (24\%) were multi-country studies or systematic reviews. Publication dates ranged from 2002 to 2016.
Cross-sectional survey designs were most common (32\%), followed by longitudinal studies including RCTs (30\%), qualitative studies (19\%), retrospective chart reviews $(12 \%)$, systematic reviews $(6 \%)$, and mixed method studies (1\%). Inclusion criteria varied across studies, though some assessed sub-populations (e.g., women choosing or discontinuing a particular contraceptive method, adolescents or young women, women living with HIV, etc.) Some studies did not limit their focus to specific contraceptive methods (31\%); the remainder focused on implants $(23 \%)$, IUDs $(12 \%)$, OCPs $(14 \%)$, injectables $(4 \%)$, the vaginal ring $(2 \%)$, or multiple specific methods (14\%).

CIMBCs as a reason for non-use, discontinuation, and dissatisfaction were the most commonly explored themes (71 studies), followed by women's attitudes specifically towards contraceptive-induced amenorrhea or other non-standard bleeding frequencies (33) and conceptual linkages between CIMBCs and health risks and side effects (33). The use of contraception for menstrual suppression was explored, in varying depth, in 28 studies. We summarized additional key themes stemming from 41 studies.

\section{Women's responses related to contraceptive-induced amenorrhea and other non-standard bleeding frequencies} Women's responses varied substantially across individuals, communities, and regions. In some studies, amenorrhea was primarily viewed negatively [43-50]. In addition to health concerns (detailed below), many women were generally suspicious of amenorrhea [44], saw it as a disadvantage of hormonal contraception [45-50], and identified menstruation as a natural state of womanhood [44, 45]. More positive views of amenorrhea emerged in some studies [48-54], mainly centering around convenience $[44,50,51,55]$ or avoidance of menstruation-associated problems (e.g., painful periods) $[47,55]$.

Across included surveys, women's preference for amenorrhea ranged between 0\% [56] (in Tunisia) and 65\% [57] (in Brazil) (Table 2) [53, 55-71]. Preferences for regular, non-monthly menstrual cycles (i.e., various durations of longer than one month but less than one year) ranged between 0\% [56] (in Indonesia) and 66\% [68] (in Mexico). Generally, amenorrhea appears more commonly preferred in North America, Europe and South America, whereas trends for other bleeding pattern preferences are less prominent (Table 2). It is important to note that over half of studies examining women's bleeding pattern preferences were conducted in North America or Europe, and that these findings may not generalize to other contexts.

Variation between studies (i.e., age, contraceptive history, relationship status, race/ethnicity, education, etc.) 


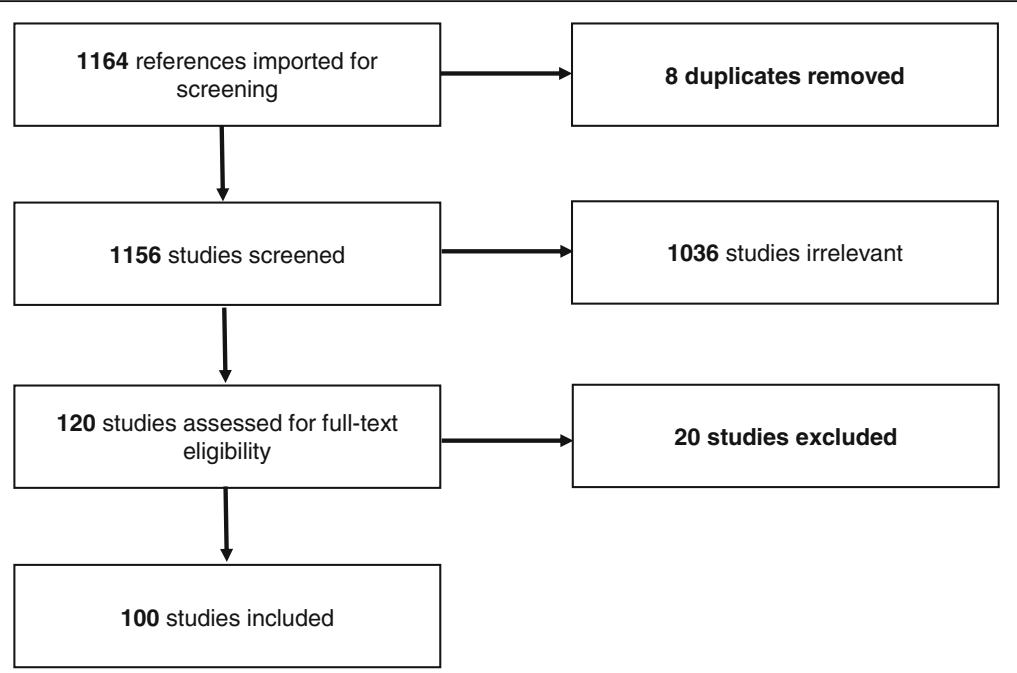

Fig. 1 Study flowchart

precludes disentangling the impact of each factor on women's preferences, but some relationships were specifically assessed in individual studies. Greater preference for amenorrhea was generally observed in either the youngest $[44,55,71]$ or the oldest groups of women surveyed $[50,64,66,69,70,72]$, while women in middle age categories (i.e., 24-34) appeared less accepting of amenorrhea [53, 60]. In contrast, no significant differences in preference for amenorrhea by age group were found in studies in Nigeria, South Africa, Scotland, Italy $[55,67]$. Younger women were also generally more likely to desire less frequent (but non-amenorrheic) menstrual bleeding patterns $[56,60,66,68,70]$. A Swiss study found that while $37 \%$ of women preferred monthly bleeding, nearly as many (32\%) preferred an interval of 2-6 months, with women aged 15-19 most likely to prefer two-monthly intervals [53]. Italian women reported no significant differences in preferences for other bleeding pattern lengths by age [67].

Three multi-country analyses showed that previous use of hormonal contraception was associated with increased willingness to consider non-standard bleeding patterns [56, 70,73], though this was not observed in two European studies $[66,69]$. Six studies in various regions described less interest in non-standard bleeding patterns among married or cohabitating women (as compared with unmarried, non-cohabitating, or divorced women) $[56,58,64]$. In the United States, black and/or Hispanic women were most likely to believe monthly menstruation is necessary [61]. In one study, white women reported being more open to amenorrhea than black women (49\% vs. $29 \%$ ), though authors noted a correlation between race and study site, preventing the differentiation of racial and regional differences [58]. In a South African study, more white women (29\%) than black women (9\%); reported a preference for amenorrhea over other bleeding patterns [55]. Other studies examined whether relationships existed between preference for amenorrhea (or other non-monthly bleeding patterns) and factors such as occupation [56, 63], parity and desire for more children [55, 66], religiosity $[44,55,56,64,65]$, and women's current bleeding characteristics [55, 58, 65, 73]; findings for each relationship varied by context, and in some cases, showed significant associations in different directions.

Some studies assessed preferences regarding menstrual regularity and flow (vs. bleeding intervals). Bleeding regularity and predictability emerged as a key preference in two multi-country studies [70, 74], while another multi-country study found that 58\% women would accept temporary irregularity if it ultimately led to fewer bleeding episodes or amenorrhea over time (ranging from 34\% of women in Russia to $76 \%$ of women in Brazil) [72]. Lighter menstruation was viewed as a contraceptive benefit in some studies $[54,58,75]$.

\section{CIMBCs as a reason for non-use, dissatisfaction, or discontinuation}

Seventy-one included studies assessed women's discontinuation, dissatisfaction, or non-use of contraception due to experience or perception of CIMBCs (Additional file 1) [43-50, 52-54, 72, 74-132]. Most pertained to a specific contraceptive method (implants: 20, IUDs: 12, combined OCPs: 10 , progestin-only and combined injectables: 4 , vaginal ring: 2), while 13 addressed multiple methods and 10 were not method-specific. While bleeding changes may have been inconsistently defined (by researchers and study participants) across studies, spotting, unpredictable, frequent or irregular bleeding were defined as negative side 
Table 1 Geographic representation of included studies

\begin{tabular}{|c|c|c|c|c|}
\hline & $\mathrm{N}$ & $\begin{array}{l}\% \text { of included studies } \\
\text { across and within } \\
\text { subregions }\end{array}$ & $\begin{array}{l}\text { Countries represented (and number of } \\
\text { studies within that country) }\end{array}$ & References \\
\hline Africa & 11 & $11 \%$ & & \\
\hline Northern Africa & 1 & $9 \%$ & Egypt (1) & {$[115]$} \\
\hline Eastern Africa & 2 & $18 \%$ & Kenya (2) & {$[107,132]$} \\
\hline Middle Africa & 0 & $0 \%$ & - & - \\
\hline Southern Africa & 2 & $18 \%$ & South Africa (2) & {$[47,122]$} \\
\hline Western Africa & 6 & $55 \%$ & Nigeria (3), Mali (1), Ghana (2) & {$[43,76,87,94,102,104]$} \\
\hline Americas & 32 & $32 \%$ & & \\
\hline $\begin{array}{l}\text { Latin America and the } \\
\text { Caribbean }\end{array}$ & 10 & $31 \%$ & Dominican Republic (1), Mexico (3), Brazil (6) & $\begin{array}{l}{[44,57,68,78,81,84,95,103,124,} \\
137]\end{array}$ \\
\hline Northern America & 22 & $69 \%$ & US (18), Canada (3), Unspecified (1) & $\begin{array}{l}{[46,58,59,61,62,71,75,85,86} \\
90-92,111,112,125-127,130 \\
133-136]\end{array}$ \\
\hline Antarctica & 0 & na & - & - \\
\hline Asia & 7 & $7 \%$ & & \\
\hline Central Asia & 0 & $0 \%$ & - & - \\
\hline Eastern Asia & 1 & $14 \%$ & China (1) & [64] \\
\hline Southeastern Asia & 1 & $14 \%$ & Thailand (1) & [114] \\
\hline Southern Asia & 3 & $43 \%$ & India (1), Bangladesh (1), Iran (1) & {$[63,83,99]$} \\
\hline Western Asia & 2 & $29 \%$ & Turkey (2) & {$[45,123]$} \\
\hline Europe & 20 & $20 \%$ & & \\
\hline Eastern Europe & 0 & $0 \%$ & - & - \\
\hline Northern Europe & 10 & $50 \%$ & Finland (1), Ireland (1), Netherlands (1), UK (7) & $\begin{array}{l}{[51,52,82,97,98,100,105,109,} \\
113,145]\end{array}$ \\
\hline Southern Europe & 6 & $30 \%$ & Italy (3), Spain (3) & {$[66,67,77,79,88,138]$} \\
\hline Western Europe & 4 & $20 \%$ & Austria (2), Germany (1), Switzerland (1) & {$[48,53,60,110]$} \\
\hline Oceania & 6 & $6 \%$ & & \\
\hline $\begin{array}{l}\text { Australia and New } \\
\text { Zealand }\end{array}$ & 6 & $100 \%$ & Australia (5), New Zealand (1) & {$[54,96,106,121,139,141]$} \\
\hline $\begin{array}{l}\text { Melanesia, Micronesia, } \\
\text { Polynesia }\end{array}$ & 0 & $0 \%$ & & - \\
\hline $\begin{array}{l}\text { Multi-country studies or } \\
\text { systematic reviews }\end{array}$ & 24 & $24 \%$ & $\begin{array}{l}\text { Australia, Austria, Belgium, Brazil, Canada, } \\
\text { Chile, China, Czech Republic, Dominican } \\
\text { Republic, Finland, France, Germany, Hungary, } \\
\text { Indonesia, Israel, Italy, Japan, Kenya, Netherlands, } \\
\text { New Zealand, Nigeria, Norway, Poland, Russia, } \\
\text { Scotland, Slovakia, South Africa, Spain, Sweden, } \\
\text { Switzerland, Thailand, Tunisia, Turkey, Ukraine, } \\
\text { UK, US, Zimbabwe; unspecified countries in } \\
\text { Europe, Asia, and Western Europe; countries } \\
\text { included in studies in systematic reviews }\end{array}$ & $\begin{array}{l}{[49,50,55,56,65,69,70,72-74} \\
80,89,93,101,108,116-120,128 \\
131,140,160]\end{array}$ \\
\hline
\end{tabular}

effects in 42 studies [43, 48-50, 52-54, 72, 75, 77, 78, 81, $82,84,86,88-92,94,97,98,100,102,105,106,108-111$, $116-119,122,123,127-129,132], 22$ studies noted that heavy or prolonged bleeding were poorly tolerated $[49,53$, 54, 77, 83, 84, 91, 92, 98, 101, 103, 104, 106, 110, 111, $113-115,123,129,131]$, and 22 studies found contraceptive-induced amenorrhea to be problematic [44,
$48-50,76,78,79,84,86,90,91,98,100-102,106,113$, $115,123]$.

\section{Non-use}

Ten studies (including seven qualitative studies) examined whether CIMBCs caused women to hesitate or decide not to use contraception $[43,45-47,49,74,82,87$, 


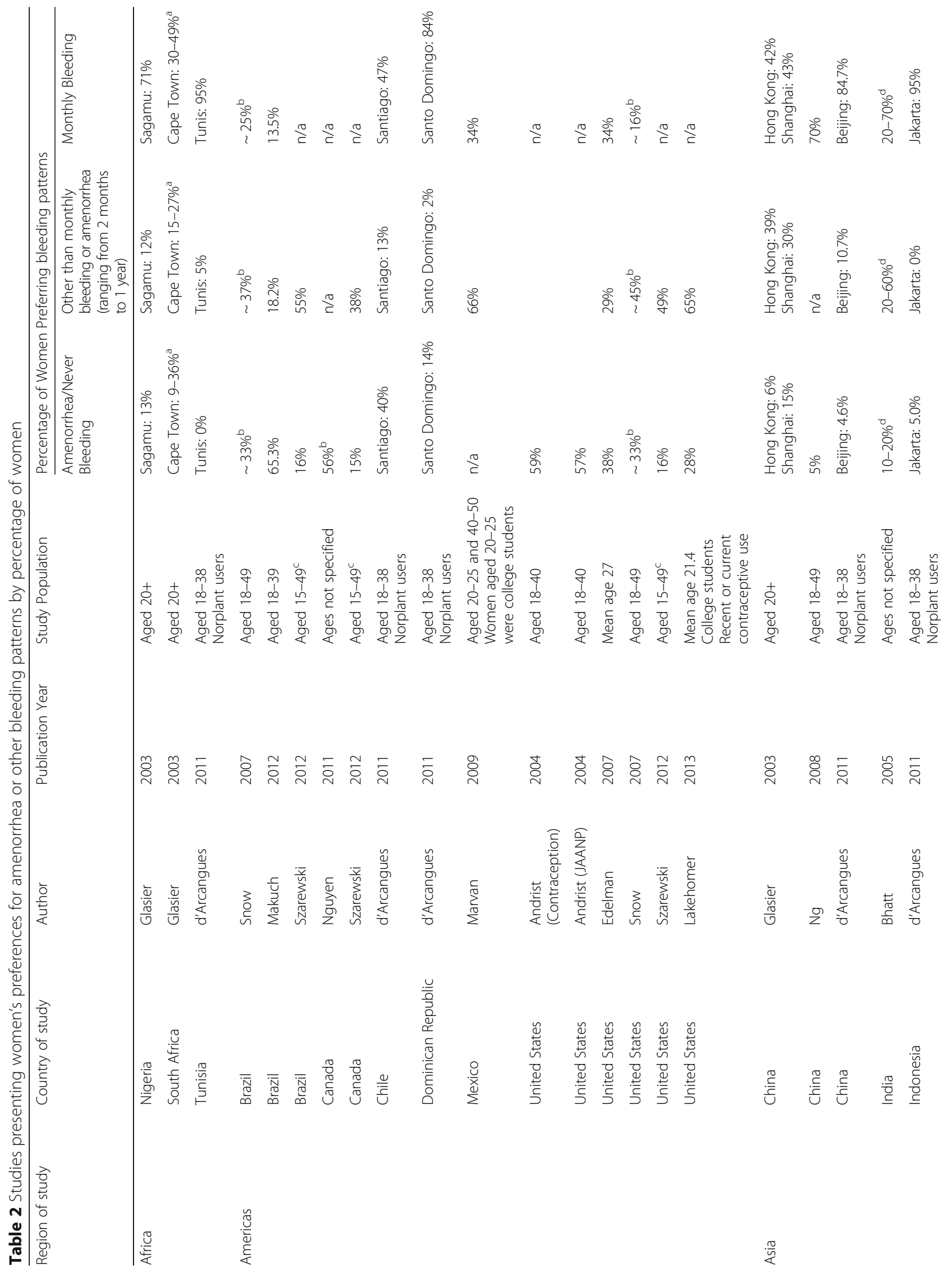




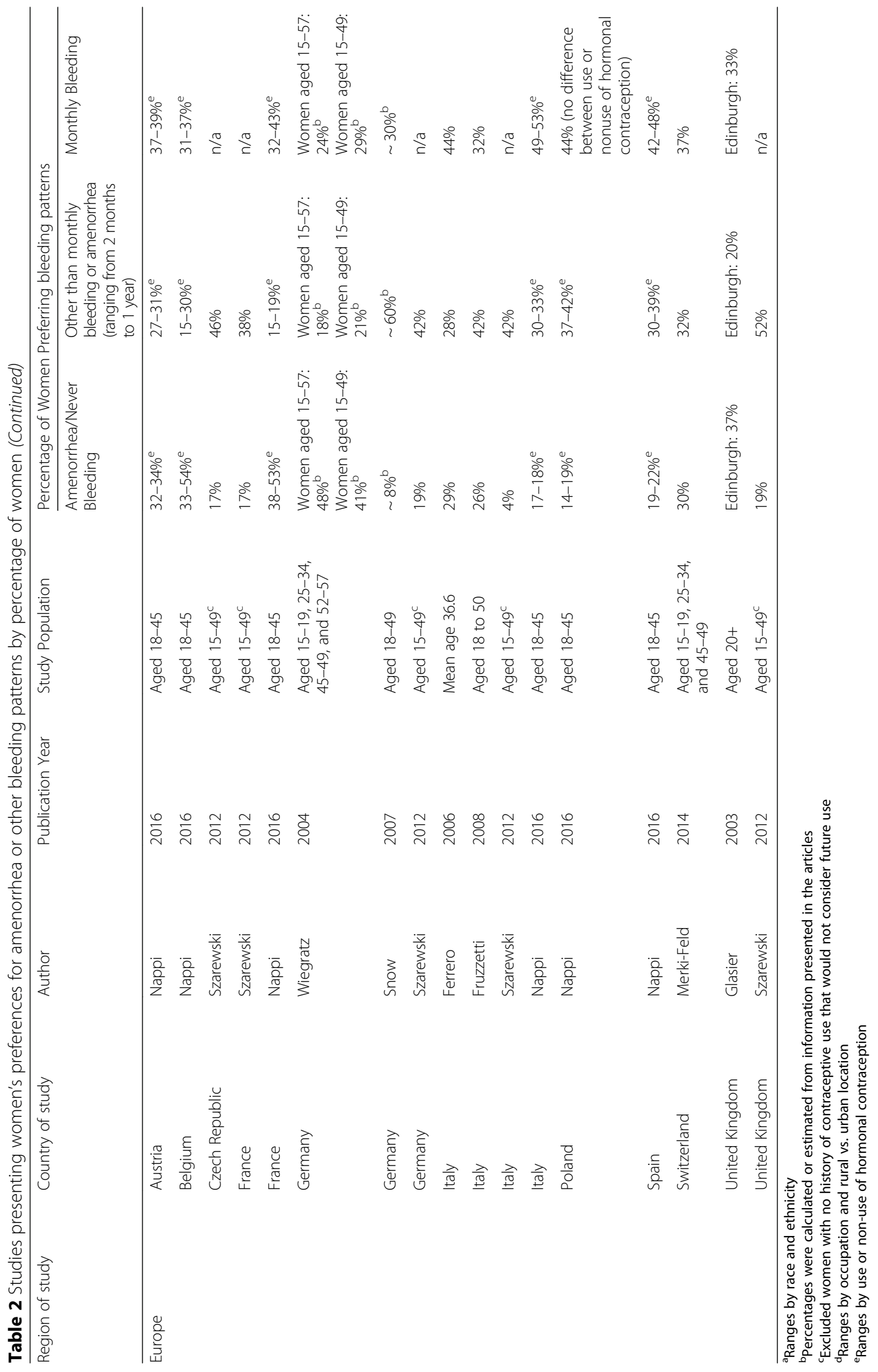


104, 106]. A cross-sectional study on long-acting reversible contraception (LARCs) in the UK reported that the potential for irregular bleeding disincentivized method use [82]. A systematic review on LARCs found that though various CIMBCs were perceived both positively and negatively, heavy or irregular bleeding were generally viewed negatively [49]. A large study in eight developed countries among women interested in combined hormonal methods found that small proportions (3-5\%) did not choose the contraceptive pill, ring or patch due to the potential for the absence of regular bleeding [74]. Women in qualitative studies in the US and New Zealand were concerned about using amenorrhea-inducing methods because it would complicate knowing if they were pregnant [46, 106], or (in New Zealand and Turkey) because they viewed menstruation as normal and healthy $[45,106]$. Various health concerns related to CIMBCs (detailed below), also impacted willingness to use contraception $[43,47,87]$.

\section{Dissatisfaction}

Twenty-one studies addressed how CIMBCs impacted method satisfaction $[48-50,52,53,75,76,83,84,88,90$, 92, 97, 99, 105, 107-110, 114, 132]; 13 of these calculated estimates of bleeding-related reasons for dissatisfaction [53, 75, 76, 83, 84, 92, 105, 107-110, 114, 132]. We did not detect clear patterns in dissatisfaction for CIMBCs by geographic area, but several studies showed that despite dissatisfaction with specific aspects of a given method, some women may nonetheless choose to continue use.

Various methods induce different bleeding changes (i.e., injectables often induce amenorrhea, copper IUDs are associated with a temporary increase in heavy bleeding, etc.) $[14,16]$. Menstrual abnormalities were the most common complaint among women using injectables in studies in Mexico and Nigeria [76, 84]. Among the $71 \%$ of Nigerian progestin-only injectable users who were dissatisfied with CIMBCs, amenorrhea was the most commonly disliked change (67\% of those dissatisfied) [76]. Similar proportions of progestin-only (24\%) and combined injectable (Cyclofem) (22\%) users in Kenya described CIMBCs as their least liked method characteristic, despite the finding that women using progestin-only injectables were much more likely to experience amenorrhea $(71 \%$ versus $21 \%$ in Cyclofem users) [107].

Among Nestorone implant users in Brazil, Chile and the Dominican Republic, the most common complaints were an increase in flow and duration of bleeding, as well as amenorrhea [108]. Similarly, half of method complaints in a retrospective medical chart review among Thai implant users were bleeding-related (prolonged bleeding, spotting, and amenorrhea) [114]. Irregular bleeding was the most commonly reported problem (22\%) among Irish implant users [105]. A Kenyan study found $7-8 \%$ of IUD and implant users reported that their bleeding patterns were not acceptable [132]. A US study of IUD and implant use found that $17-19 \%$ of participants disliked heavy or prolonged bleeding while only 5\% disliked lighter and decreased bleeding [92]. IUD users in Bangladesh most commonly reported heavy bleeding as an unwanted side effect [83]. Spotting between periods led $12 \%$ of hormonal IUD users in the US to report disliking the method, while another 13\% disliked the IUD for factors which included other bleeding-related reasons [75]. Only 6\% of women with hormonal IUD experience in Austria indicated that they were "really not satisfied" with their bleeding pattern [110]. Lastly, a clinical study comparing a standard and tailored use of OCPs (with the assumption of less bleeding with tailored regimens), found lighter bleeding to be among the most commonly reported side effect, but surprisingly, more women using a tailored regimen were dissatisfied with bleeding patterns (3\% versus 11\%) [109].

\section{Switching and discontinuation}

Sixty studies $[44,47,48,50,52,54,72,75-81,83-91$, 93-103, 105, 107-123, 125-131] reported at least one subject discontinuing or switching a contraceptive method specifically due to bleeding changes, and 40 measured the proportion of subjects doing so $[48,54$, 72, 75-81, 83-86, 88, 89, 91, 93-96, 98, 100-102, 105, $107-110,112-115,121,123,125-128,130]$. Several included studies (40) found that CIMBCs were either the leading cause or among the top reasons for discontinuation $[44,48,52,54,75-79,83-87,89,91,94-100,102$, $105,107,108,110,112,113,115,121-123,125-129$, 131]. Three studies reported that between 0 and $10 \%$ of discontinuers did so due to CIMBCs [81, 112, 114], 9 reported 11-25\% [48, 54, 88, 94, 108-110, 128, 130], 13 reported $26-50 \%[75,77,78,80,84,89,101,102,105$, $109,115,121,129]$ and 15 reported over $50 \%$ [54, 76, 79, 83-86, 95, 96, 98, 100, 121, 123, 125, 126]. Detailed information on studies assessing discontinuation according to specific contraceptive method is available in Additional file 2.

\section{Conceptual linkages between CIMBCs and health risks or side effects}

Thirty-three studies had information pertinent to this topic, including six in Africa [43, 47, 87, 104, 107, 122], nine in the Americas [44, 46, 57, 103, 133-137], five in Asia [45, 63, 64, 83, 114], nine in Europe [51, 52, 60, 67, 88, 97, 109, 110, 138], two in Oceania [106, 139], and two in multi-country studies [50, 140]. In studies across multiple countries, including Mali, Kenya, South Africa, Brazil, Spain, the Dominican Republic, 
Canada, the US, and the UK, regular menstruation was viewed by many women as a marker of health and fertility, as well as providing reassurance of not being pregnant $[47,50,51,57,87,103,133-135,137$, 138]. Women in South Africa, Mali, and Brazil, adolescents in South Africa and the US, rural housewives in India, and poor urban women in Turkey perceived that menstruation cleansed the body of "dirty blood" or toxins [44-47, 63, 87, 122].

However, associations between menstruation and health were not uniformly positive. Some women in South Africa and Mali perceived menstruation as positive but simultaneously dirty, inconvenient, or uncomfortable [47, 50, 87]. Chinese women reported needing to take an average of 3.3 sick days from work per year due to painful menstruation [64]. A higher percentage of Spanish women in one survey reported not liking anything about menstruation other than feeling it was natural and healthy [138]. Some CIMBCs were perceived as beneficial, for example, in Spain and Austria, women initiating LNG-IUD use reported appreciating reductions in heavy menstrual bleeding and painful periods $[88,110]$. For some South African women, living with HIV raised anxieties about the need to protect family members from items soiled by their blood, as well as fears that not menstruating might "keep the HIV inside" of their bodies $[47,50]$. In a multi-country study among women living with HIV the proportion who perceived amenorrhea as an ideal feature in a contraceptive method was generally low: $28 \%$ in Kenya, 22\% in South Africa, and 0\% in Brazil [50].

Contraceptive-induced amenorrhea raised health-related concerns in several settings. Young Malian women viewed amenorrhea as abnormal or indicative of illness [87]. Multiple study participants in South Africa and Ghana, as well as adolescents in the US, noted perceiving amenorrhea as "blocked" blood, and believed that if this blood did not exit the body, health issues (or even death) might ensue $[43,46,47,122]$. Some South African adolescents also perceived that "blocked" blood eventually coming out too quickly could also lead to death [122]. A range of symptoms were understood as being caused by amenorrhea, including nosebleeds, blood clots, fibroids, bad skin, anorexia, weight gain, and more [44, 47, 104, 122]. Among adolescents in the US, amenorrhea (and irregular bleeding) also caused doubts about the effectiveness of their contraceptive method, and accompanying fears about being pregnant [46].

However, contraceptive-induced amenorrhea was not consistently perceived negatively. For example, some young abortion patients in New Zealand felt that it had both positive and negative aspects [106], and some students in India preferred it, so long as it didn't interfere with their feminine looks [63]. In a Kenyan randomized trial comparing a progestin-only injectable (DMPA) to a combined injectable (Cyclofem), 71\% of DMPA users and $12 \%$ of Cyclofem users were amenorrheic by 12 months. $78 \%$ of women in both groups said what they liked most about their method was the "lack of side effects" - suggesting that most did not view amenorrhea as a side effect [107].

In addition to amenorrhea, health concerns around heavy or prolonged bleeding emerged across several contexts $[46,104,114]$. For example, Bangladeshi women who discontinued an IUD due to heavy bleeding said they felt emotionally and physically unwell, were unable to participate in various activities, and described being in a "bloodless body" [83]. Some also said this evoked fears about uterine perforation and potential death [83]. Some Malian woman also linked heavy bleeding to the possibility of death, or other health issues such as cancer [87]. Similarly, among some women in the UK, prolonged or heavy bleeding signified bodily damage or a "body out of control" [51, 97].

A key theme, generally related to amenorrhea but sometimes to excessive bleeding, pertained to fears of becoming permanently infertile [46, 87]. For example, in South Africa, some women perceived that "blocked" blood (amenorrhea) would cause the womb to "get tired" or that excessive bleeding would lead to infertility $[47,122]$. In Turkey, some women described fears that using contraception would cause their ovaries to get "lazy" [45]. However, some infertility fears were linked to the hormonal content of some contraceptives, rather than to bleeding changes [50].

Ten studies, primarily from higher-income countries, provided information specifically pertinent to how women perceive use of menstrual suppression in relation to health concerns $[44,52,60,67,109,133,135,136,139,140]$. The largest of these was an online survey of over 4000 women across eight countries (Brazil, Canada, the Czech Republic, France, Germany, Italy, the UK, and the US) [140]. Health concerns were substantial for women with respect to menstrual suppression, with $42 \%$ of women believing that postponing monthly bleeding would have negative effects on their health [140].

\section{Women's responses to deliberate menstrual suppression}

Menstrual suppression involves using certain types of hormonal contraception in specific ways to deliberately avoid monthly bleeding, either on a short-term basis for specific life events (i.e., travel, honeymoon, athletic events, etc.) or on a longer-term basis to suppress menstruation for longer timeframes. Among 28 studies on menstrual suppression $[44,51-53,57,59-62,64,66-68,70,78,93,103,109$, $111,127,133-136,138-141]$, many themes were similar to those described above, and when relevant, these studies are included in sections above. Given this, and since menstrual suppression represents the deliberate manipulation 
of the menstrual cycle (rather than as a "consequence" of standard contraceptive use, the main focus of this review), we address this topic only briefly.

The majority of studies focused on suppression through OCP use $[57,59-61,66,68,70,93,103,109$, $111,133-136,138-141]$, with 6 to $65 \%$ of study participants reporting having suppressed menstruation $[57,59-61,66,68,70,133-136,138-141]$. Some studies discuss other hormonal methods $[66,78,139]$ or use of hysterectomy to suppress menstruation [139]. Other considerations related to menstrual suppression included: practicality and convenience of avoiding menstruation $[52,59,135,139-141]$, fertility concerns [60, 61, 67, $134,136,139]$, perceptions of short and long term health effects [44, 51, 60,61, 64, 67, 134, 136, 139, 140], cost of menstrual suppression [134] and feminine hygiene products $[52,135]$, impact of menstruation on activities [51, $59,64,66,70,135]$, management of pain, heavy bleeding or other undesirable menstrual symptoms $[51,53,59,60$, $62,135,136,141]$, concerns about becoming pregnant while suppressing menstruation [52, 60, 140], and information from or recommendation of a medical provider about menstrual suppression $[57,59,61,138]$.

\section{Other emergent themes}

Several additional themes emerged. For example, multiple studies addressed how CIMBCs (or menstruation) positively or negatively impacted daily activities, including participation in domestic, work, school, sports, social, or religious life; sexual or emotional relationships; concentration or sleeping ability; or clothing choices and the need to manage excessive amounts of laundry (to wash fabrics used to absorb blood) $[44,50,51,56,57,63,64,66,69,70$, 83, 87, 133, 137]. Bangladeshi women who discontinued IUD use due to perceived excessive menstrual bleeding described guilt for being unable while bleeding to pray or contribute to household tasks (e.g., tending cows or cooking) [83]. Some Indian women appreciated bleeding as it provided temporary relief from domestic chores [63], and in Brazil, an acceptable excuse to refuse sexual intercourse [44]. Several Malian women described how excessive bleeding increases concern that male partners may seek extramarital partnerships, as men are discouraged from sex with menstruating women [87]. In this context, non-pregnant amenorrheic women may be perceived as promiscuous, which can lead to social ostracization and divorce [87]. Given cultural prohibitions around participation in various activities during menstruation, CIMBCs can also "out" women attempting to use a method clandestinely $[87,106]$. Furthermore, many of the studies reflecting these themes were conducted in low-resource settings, where menstrual hygiene products may be less accessible [142]. In a multi-country survey across eight largely higher-income countries, nearly one-third of women felt menstrual bleeding had a severe negative impact on their daily life, and most preferred to reduce bleeding frequency [70].

A related body of evidence measured favorable and unfavorable attitudes towards menstruation and associated factors [51, 53, 55, 58, 60, 62, 65, 68, 70, 103, 137]. For example, $62 \%$ of women in a Brazilian study [137] and $69 \%$ of women in a US study [58] noted disliking menstruation. Inconvenience and pain were common reasons $[51,58,60,65,137]$, while feeling healthy, natural, womanly, or being reassured of not being pregnant were common themes for liking menstruation $[45,51,55,58,60,103,137]$.

Providing information on potential or expected side effects, including CIMBCs, is a recommended component of comprehensive contraceptive counseling [143, 144]. While several studies indicated that at least some participants received some contraceptive counseling (prior to or during method use) on CIMBCs [45, 48, 72, 75, 87, 97, 98, 103, 113-115, 123, 124, 145] our search strategy identified few studies measuring the impact of counseling on method satisfaction or continuation. A few studies suggested that good contraceptive counseling may have improved method satisfaction or continuation rates, but none reported specific results to this effect $[75,103]$. A study among LARC users in Brazil found no significant difference in discontinuation rates among women receiving "routine" versus "intensive" counseling including CIMBCs [124]. General family planning counseling (which may not have included appropriate bleeding-specific information) had no overall effect on discontinuation rates of IUD, implants and injectables among Egyptian women [115]. Among the implant users in the study, however, those experiencing longer bleeding lengths had a $2 \%$ increased hazards of discontinuation without counseling, and an $18 \%$ increased hazards of discontinuation with counseling; this seemingly counterintuitive result might relate to lack of adequate, method-specific counseling [115]. Also surprisingly, Dutch women specifically counseled on CIMBCs had lower 12- and 24-month implant continuation rates (72 and $53 \%$, respectively) than previous similar studies [113]. Only one study included information about participants' assessment of the quality of counseling they received on CIMBCs [75].

Some studies directly explored women's perceptions of how bleeding patterns impacted their choice of contraception [51, 82], including tradeoffs between contraceptive effectiveness and CIMBCs [72]. For example, a survey administered in nine countries found that the percent of women who would consider using one of the most effective contraceptive methods, even if it were associated with menstrual cycle changes, ranged from $24 \%$ (in Italy) to 53\% (in the UK and Brazil) though overall, 
younger women were less likely to consider this tradeoff [72]. Overall, $42 \%$ of women in that study would consider using one of the most effective contraceptive methods even when informed that their menstrual cycle would change and may become irregular [72]. Other studies examined which component of CIMBCs worried women [115] or the proportion of women who contacted health care providers to discuss bleeding concerns [85]. Finally, a few studies addressed impacts of contraception on menstrual-related issues (such as menstrual pain) $[48,101,123]$, or used vignettes pertaining to women of different ages, relationships statuses, and life events, to examine how participants thought through various scenarios involving CIMBCs [43].

\section{Conclusions}

Substantial variability exists in terms of how women respond to CIMBCs - including what they prefer and what they are willing to tolerate - and these responses are shaped by individual and social influences. For example, women's stated preferences for amenorrhea ranged from 0 to $65 \%$ across included surveys. Contraceptive-induced amenorrhea may be viewed more positively in certain geographical regions (e.g., the Americas, some European and South American countries; though little comparative data is available in Africa) and by certain subpopulations (e.g., women younger than 24 or older than 34). In several multi-country surveys, prior use of hormonal contraception was associated with greater openness to non-monthly bleeding patterns. While several included studies suggest that CIMBCs do substantially impact contraceptive non-use, dissatisfaction, and discontinuation, most studies assessing this domain specifically evaluated discontinuation. Specific menstrual bleeding pattern preferences vary widely across contexts and sub-populations, but it is clear that CIMBCs can impact multiple aspects of women's daily lives, including health-related perceptions, experiences, and fears, as well as participation in domestic, work, school, sports, social, religious, sexual, or other activities $[146,147]$. Furthermore, several studies suggest that menstrual regularity (whether as part of normal menstruation or less frequent bleeding patterns) may be perceived positively [70, 74], and unexpected bleeding may be perceived negatively $[43,46,48-54,72,75,77,78,81$, $82,86,88-92,94,97,98,100,102,105,106,108-111$, $114,116-119,122,123,127-129,132]$. Monthly bleeding may relate to the reassurance of not being pregnant $[51,52,55,57,58,60,140]$ and perceptions of continued fecundity $[46,47,58,60,67,87,106,134,137,139]$. As such, women's responses to CIMBCs (and the factors correlated with those responses) should be broadly recognized as a key issue in contraceptive research, counseling, and product development. A substantial proportion of relevant studies come from Europe, Northern America, and other higher-income settings, so studying these issues in other regions (e.g., Africa, Asia, and Oceania) is particularly needed, as results from these contexts may not generalize to lower-income settings.

This scoping review fills a key gap in the literature by mapping recent data on women's responses and preferences to CIMBCs, and follows methodological guidance for conduct of scoping reviews [37]. Limitations of this review include searching a single database (PubMed) and the challenge of crafting a search strategy that is both specific and sensitive to such a broad topic of inquiry. We iteratively tested multiple search strategies, hand-searched reference lists of key studies, and consulted with an expert group to identify additional relevant articles. Crafting clear study inclusion criteria was also challenging, given the wide variety of pertinent study designs. To maximize comprehensiveness and feasibility while minimizing inclusion of irrelevant or minimally informative studies, we required that studies reference women's responses to CIMBCs in the title and/or abstract; this may have influenced which studies were included. For example, among studies assessing contraceptive discontinuation, if CIMBCs were not a top reason (and thus not mentioned in the abstract), inclusion was less likely, which could mean that other reasons for discontinuation are underrepresented among our included studies. However, among included studies, we did attempt, where possible, to determine whether CIMBCs or other factors were the primary reasons for discontinuation (or other outcomes). While scoping reviews are intended to broadly map a domain in the literature, future systematic reviews assessing multiple reasons for contraceptive discontinuation could assess whether this approach to study inclusion impacted our findings. Finally, like all scoping reviews, we did not assess underlying study quality [38].

Several recommendations for contraceptive researchers, providers, and product developers emerge from this review. For example, in large, nationally representative surveys, inclusion of response options more specific than "side-effects" or "health concerns" pertaining to CIBMCs would enable more precise quantification of the association of CIMBCs with unmet need for family planning and contraceptive discontinuation. Longitudinal studies collecting information on bleeding patterns should adhere to guidelines used to classify bleeding patterns, to enhance comparability across studies $[26,148]$. Collecting and controlling for key variables believed to influence responses to CIMBCs (i.e., age, prior contraceptive use, etc.) could also enhance comparability. In addition to disparities in geographic distribution of studies, several overall research gaps remain, 
including understanding how women's knowledge of various physiological processes (i.e., menstruation, contraceptive mechanisms of action, etc.) impacts responses to bleeding patterns; the impact of contraceptive-induced amenorrhea or irregular bleeding on timing of pregnancy recognition and reproductive options; and linkages between CIMBCs and menstrual hygiene management. Researchers should adopt a neutral stance when asking women about menstrual preferences (e.g., avoid assuming that amenorrhea is viewed positively or negatively), and should be familiar with the range of instruments which have been used to investigate women's responses to various menstrual-related issues (e.g., Menstrual Attitudes Questionnaire, Menstrual Distress Questionnaire, Attitudes towards Menstrual Suppression Instrument, Inconvenience Due to Women's Monthly Bleeding instrument, etc.); consideration of using common, standardized measurements across studies may also be valuable.

Contraceptive providers should take women's concerns about CIMBCs seriously and address them in a non-judgmental manner, as these changes may not be viewed merely as a minor side effect and, in some cases, may have profound impacts on multiple aspects of women's lives. Given varied views on whether monthly bleeding is necessary for optimal health [135], providers should also be aware that some individuals may be skeptical about medical advice regarding what is "safe" or "normal". Future work could help to clarify paradoxical findings [115] or investigate limited impacts of some counseling approaches [149]. Development of a method-specific tool to assist providers in counseling and treatment options around CIMBCs may be useful, particularly for contraceptive methods that result in variable bleeding patterns in different women [150]. Similarly, prospectively eliciting individual's bleeding preferences could assist in helping them select a method most likely to suit their needs, and identification of factors that could help predict which side effects (including specific bleeding changes) a woman might expect to experience when initiating a contraceptive method may assist providers to better tailor contraceptive counseling [151]. Addressing some women's concerns that menstrual irregularity is associated with reduced contraceptive effectiveness may be important [46]. Finally, providers and contraceptive users should be aware of treatment options for management of unwanted CIMBCs [152-155] (e.g., non-steroidal anti-inflammatory drugs, combined oral contraceptive pills, etc.), though more research is also needed to refine treatment options and improve bleeding patterns and user satisfaction/ acceptability. Some evidence does suggest that treating undesirable CIMBCs may improve contraceptive continuation [156, 157].
Development of new contraceptive or MPT products hold promise from a public health perspective [158], but actual impact may be inhibited if acceptability (and consequently, adherence) is not adequately addressed $[146,159]$. Studies on responses to CIMBCs within regions which would be targeted for rollout of new products may be useful during development stages, in order to enhance product acceptability. Furthermore, provision of clear information around expected CIMBCs for new products can help providers assist women to anticipate and manage these changes, and help avoid negative perceptions from becoming associated with new products. Ideally, product development will continue to expand method options to meet diverse women's ideal contraceptive profiles (including preferred bleeding patterns), so contraceptors are not required to tolerate undesirable product characteristics in order to use effective pregnancy prevention strategies.

Overall, the importance of how women perceive and respond to CIMBCs may be currently underappreciated in the reproductive health field, despite likely - and potentially substantial - impacts on key issues such as contraceptive discontinuation and unmet need for modern contraception. Contraceptive researchers, providers, and product developers - in addition to policy-makers, service delivery suppliers, and funders - can use the body of knowledge summarized in this scoping review to better ensure that women and girls have a reliable supply of contraceptive (and MPT) options that align with their preferences and effectively prevent unintended pregnancies and other adverse outcomes.

\section{Additional files}

Additional file 1: Summary of studies including information on contraceptive discontinuation, dissatisfaction or nonuse due to bleeding related side effects. (DOCX $29 \mathrm{~kb})$

Additional file 2: CIMBCs and discontinuation by specific method. (DOCX $19 \mathrm{~kb}$ )

\section{Acknowledgements \\ We are grateful to the individuals who agreed to participate in our expert consultation and who provided valuable input and feedback, including (in alphabetical order by last name): Dr. Diana Blithe, Dr. Jeanne Marrazzo, Dr. Carolina Sales Vieira, Dr. Cynthia Woodsong, and Dr. Bethany Young-Holt. We also thank Dr. Ann Biddlecom and Dr. Gilda Sedgh, Ms. Jesse Boyer, and Ms. Colette Rose for their feedback on earlier drafts of the manuscript.}

\section{Funding}

This study was made possible by UK Aid from the UK Government. Additional support was provided by the Guttmacher Center for Population Research Innovation and Dissemination (NIH grant 5 R24 HD074034). The views expressed are those of the authors and do not necessarily reflect the positions or policies of the donors.

Availability of data and materials

Data sharing is not applicable to this article as no datasets were generated or analysed during the current study. 


\section{Authors' contributions}

$\mathrm{CP}$ primarily conceived of the idea for the manuscript and led the literature search. $C P, R H$, and $A B$ reviewed and abstracted full-text studies, participated in the expert consultation, and drafted the manuscript. All authors read and approved the final manuscript.

\section{Ethics approval and consent to participate}

Not applicable.

\section{Consent for publication}

Not applicable.

\section{Competing interests}

The authors declare that they have no competing interests.

\section{Publisher's Note}

Springer Nature remains neutral with regard to jurisdictional claims in published maps and institutional affiliations.

Received: 6 February 2018 Accepted: 15 June 2018

Published online: 26 June 2018

\section{References}

1. Guttmacher Institute. Adding it up: investing in contraception and maternal and newborn health, 2017. New York: Guttmacher Institute; 2017. Available from: https://www.guttmacher.org/sites/default/files/factsheet/adding-it-upcontraception-mnh-2017.pdf

2. Bearak J, Popinchalk A, Alkema L, Sedgh G. Global, regional, and subregional trends in unintended pregnancy and its outcomes from 1990 to 2014: estimates from a Bayesian hierarchical model. Lancet Glob Health. 2018;6: e380-389.

3. Sedgh G, Ashford LS, Hussain R. Unmet need for contraception in developing countries: examining women's reasons for not using a method. The Guttmacher institute; 2016. Available from: http://repositorio.gire.org. mx/bitstream/123456789/2049/1/unmet-need-for-contraception-indeveloping-countries-report.pdf.

4. Bradley SEK, Schwandt HM, Khan S. Levels, Trends, and Reasons for Contraceptive Discontinuation. Calverton, MD: ICF Macro; 2009. Sep. Report No: 20

5. Sedgh G, Hussain R. Reasons for contraceptive nonuse among women having unmet need for contraception in developing countries. Stud Fam Plan. 2014:45:151-69.

6. Williamson LM, Parkes A, Wight D, Petticrew M, Hart GJ. Limits to modern contraceptive use among young women in developing countries: a systematic review of qualitative research. Reprod Health. 2009;6:3.

7. DHS Model Questionnaire - Phase 7 (English, French). [cited 28 Mar 2017]. Available from: http://dhsprogram.com/publications/publication-DHSQ7DHS-Questionnaires-and-Manuals.cfm

8. PMA2020 Data | PMA2020 [Internet]. [cited 28 Mar 2017]. Available from: http://pma2020.org/pma2020-data

9. Diamond-Smith N, Campbell M, Madan S. Misinformation and fear of side-effects of family planning. Cult Health Sex. 2012;14:421-33.

10. Wells E. Countering myths and misperceptions about contraceptives. Seattle, WA: PATH; 2015. p. 1-8. Available from: http://www.path.org/publications/ detail.php?i=2525

11. Campbell M, Sahin-Hodoglugil NN, Potts M. Barriers to fertility regulation: a review of the literature. Stud Fam Plan. 2006;37:87-98.

12. Morse JE, Rowen TS, Steinauer J, Byamugisha J, Kakaire O. A qualitative assessment of Ugandan women's perceptions and knowledge of contraception. Int J Gynaecol Obstet Off Organ Int Fed Gynaecol Obstet. 2014;124:30-3.

13. Burke HM, Ambasa-Shisanya C. Qualitative study of reasons for discontinuation of injectable contraceptives among users and salient reference groups in Kenya. Afr J Reprod Health. 2011;15:67-78.

14. Hatcher RA, Trussell J, Nelson AL, Cates, Jr. W, Kowal D, Policar MS. Contraceptive Technology. 20th ed. Ardent Media; 2012.

15. López-Picado A, Lapuente O, Lete I. Efficacy and side-effects profile of the ethinylestradiol and etonogestrel contraceptive vaginal ring: a systematic review and meta-analysis. Eur J Contracept Reprod Health Care Off J Eur Soc Contracept. 2017;22:131-46.
16. National collaborating centre for women's and children's health (UK). Long-acting reversible contraception: The effective and appropriate use of long-acting reversible contraception. 2005.

17. Sznajder KK, Tomaszewski KS, Burke AE, Trent M. Incidence of discontinuation of long-acting reversible contraception among adolescent and young adult women served by an urban primary care clinic. J Pediatr Adolesc Gynecol. 2017;30:53-7.

18. Belsey EM. Regulation TF on L-ASA for F, others. The association between vaginal bleeding patterns and reasons for discontinuation of contraceptive use. Contraception. 1988;38:207-25.

19. Grant C, Serrani M, Vogtländer K, Parke S, Briggs P. Continuation rates, bleeding profile acceptability, and satisfaction of women using an oral contraceptive pill containing estradiol valerate and dienogest versus a progestogen-only pill after switching from an ethinylestradiol-containing pill in a real-life setting: results of the CONTENT study. Int J Womens Health. 2016;8:477-87.

20. Kibira SPS, Muhumuza C, Bukenya JN, Atuyambe LM. "I Spent a Full Month Bleeding, I Thought I Was Going to Die..." A Qualitative Study of Experiences of Women Using Modern Contraception in Wakiso District, Uganda. Mintzes B, editor. Plos One. 2015;10:e0141998.

21. Inoue K, Barratt A, Richters J. Does research into contraceptive method discontinuation address women's own reasons? A critical review. J Fam Plann Reprod Health Care. 2015;41(4):292-9. jfprhc-2014

22. Staveteig S. Fear, opposition, ambivalence, and omission: results from a follow-up study on unmet need for family planning in Ghana. PLoS One. 2017;12:e0182076.

23. Henry R. Contraceptive practice in Quirino province, Philippines: Experiences of side effects. 2001 [cited 5 Jan 2017]; Available from: http://dhsprogram. com/publications/publication-QRS1-Qualitative-Research-Studies.cfm

24. Jacobstein R, Polis C. Progestin-only contraception: Injectables and implants. Best Pr Res Clin Obstet Gynaecol. 2014;28:795-806.

25. Hubacher D, Chen P-L, Park S. Side effects from the copper IUD: do they decrease over time? Contraception. 2009;79:356-62.

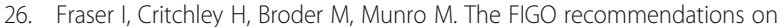
terminologies and definitions for normal and abnormal uterine bleeding. Semin Reprod Med. 2011;29:383-90.

27. Belsey EM, Farley TMM. The analysis of menstrual bleeding patterns: a review. Appl Stoch Models Bus Ind. 1987:3:125-50.

28. Khan R, MacQuarrie KLD, Nahar Q, Sultana M. The men are away: pregnancy risk and family planning needs among women with a migrant husband in Barisal, Bangladesh. 2016 [cited 5 Jan 2017]; Available from: http://dhsprogram.com/publications/publication-FA98Further-Analysis.cfm

29. Yoder PS, Guèye M, Konaté $M$. The use of family planning methods in Mali: The how and why of taking action. 2011 [cited 5 Jan 2017]; Available from: http://dhsprogram.com/publications/publication-QRS18-Qualitative-ResearchStudies.cfm

30. Mansour D, Gemzell-Danielsson K, Inki P, Jensen JT. Fertility after discontinuation of contraception: a comprehensive review of the literature. Contraception. 2011; 84:465-77.

31. Dehlendorf C, Levy K, Kelley A, Grumbach K, Steinauer J. Women's preferences for contraceptive counseling and decision making. Contraception. 2013;88: 250-6.

32. National Institute of Population Studies (NIPS) [Pakistan], ICF International. Pakistan Demographic and Health Survey 2012-13. Islamabad, Pakistan and Calverton, MD: NIPS and ICF International; 2013.

33. Statistics Indonesia (Badan Pusat Statistik-BPS), National Population and Family Planning Board (BKKBN), Kementerian Keschatan (Kemenkes-MOH), ICF International. Indonesia Demographic and Health Survey 2012. Jakarta, Indonesia; 2013 p. 544

34. Bagnan JA T, Aboubakar M, Tognifode V, Lokossou MSHS, Obossou AAA, Salifou K, et al. Side Effects of Hormonal Contraception of Patients in the Family Planning of Centre University Hospital of Mother and Child Lagoon, Cotonou (Benin). Gynecol Obstet . 2017 [cited 7 May 2018];07. Available from: https://www.omicsonline.org/open-access/side-effects-of-hormonalcontraception-of-patients-in-the-family-planningof-centre-university-hospitalof-mother-and-child-lagoon-2161-0932-1000452.php?aid=93684

35. Yangsi TT, Florent FY, Ngole ME, Nelson F. Modern contraceptive choice among patients seen at the "Cameroon National Planning Association for Family Welfare" Clinic Yaoundé. Clin Med Insights Reprod Health. 2017;11:16.https://www.ncbi.nlm.nih.gov/pmc/articles/PMC5484599/. 
36. Heise LL. Beyond acceptability: Reorienting research on contraceptive choice. World Health Organisation, beyond acceptability. Users' perspectives on contraception. 1997. pp. 6-13. Geneva: WHO.

37. Colquhoun HL, Levac D, O'Brien KK, Straus S, Tricco AC, Perrier L, et al. Scoping reviews: time for clarity in definition, methods, and reporting. J Clin Epidemiol. 2014:67:1291-4.

38. Arksey H, O'Malley L. Scoping studies: towards a methodological framework. Int J Soc Res Methodol. 2005;8:19-32.

39. WHO Task Force on Psychosocial Research in Family Planning. A cross-cultural study of menstruation: implications for contraceptive development and use. Stud Fam Plan. 1981;12:3-16.

40. Covidence systematic review software. Melbourne: Virtas Health Innovation. Available from: www.covidence.org

41. Peters MDJ, Godfrey CM, Khalil H, Mclnerney P, Parker D, Soares CB. Guidance for conducting systematic scoping reviews. Int J Evid Based Healthc. 2015;13:141-6.

42. Levac D, Colquhoun H, O'Brien KK. Scoping studies: advancing the methodology. Implement Sci. 2010;5:69.

43. Hindin MJ, McGough LJ, Adanu RM. Misperceptions, misinformation and myths about modern contraceptive use in Ghana. J Fam Plann Reprod Health Care. 2014:40:30-5.

44. Estanislau do Amaral MC, Hardy E, Hebling EM, Faúndes A. Menstruation and amenorrhea: opinion of Brazilian women. Contraception. 2005:72:157-61

45. Ay P, Hidiroglu S, Topuzoglu A, Ucar MS, Kose OO, Save D. Do perceived health risks outweigh the benefits of modern contraceptives? A qualitative study in a suburban population in Istanbul, Turkey. Eur J Contracept Reprod Health Care. 2007;12:154-61.

46. Clark LR, Barnes-Harper KT, Ginsburg KR, Holmes WC, Schwarz DF. Menstrual irregularity from hormonal contraception: a cause of reproductive health concerns in minority adolescent young women. Contraception. 2006;74:214-9.

47. Laher F, Todd CS, Stibich MA, Phofa R, Behane X, Mohapi L, et al. Role of menstruation in contraceptive choice among HIV-infected women in Soweto, South Africa. Contraception. 2010;81:547-51

48. Baldaszti E, Wimmer-Puchinger B, Löschke K. Acceptability of the long-term contraceptive levonorgestrel-releasing intrauterine system (Mirena): a 3-year follow-up study. Contraception. 2003;67:87-91.

49. Coombe J, Harris ML, Loxton D. What qualities of long-acting reversible contraception do women perceive as desirable or undesirable? A systematic review. Sex Health. 2016;13:404-419.

50. Todd CS, Stibich MA, Laher F, Malta MS, Bastos FI, Imbuki K, et al. Influence of culture on contraceptive utilization among HIV-positive women in Brazil, Kenya, and South Africa. AIDS Behav. 2011;15:454-68.

51. Newton $\mathrm{VL}$, Hoggart L. Hormonal contraception and regulation of menstruation: a study of young women's attitudes towards 'having a period'. J Fam Plann Reprod Health Care. 2015;41:210-5.

52. Graham CA, Panicker S, Shawe J, Stephenson J. Women's experiences with tailored use of a combined oral contraceptive: a qualitative study. Hum Reprod. 2013;28:1620-5.

53. Merki-Feld GS, Breitschmid N, Seifert B, Kreft M. A survey on Swiss women's preferred menstrual/withdrawal bleeding pattern over different phases of reproductive life and with use of hormonal contraception. Eur J Contracept Reprod Health Care. 2014;19:266-75.

54. Weisberg E, Bateson D, McGeechan K, Mohapatra L. A three-year comparative study of continuation rates, bleeding patterns and satisfaction in Australian women using a subdermal contraceptive implant or progestogen releasing-intrauterine system. Eur J Contracept Reprod Health Care. 2014;19:5-14

55. Glasier AF, Smith KB, van der Spuy ZM, Ho PC, Cheng L, Dada K, et al. Amenorrhea associated with contraception-an international study on acceptability. Contraception. 2003;67:1-8.

56. d'Arcangues $C$, Jackson E, Brache $V$, Piaggio $G$ \& on behalf of the study group on progestogen-induced vaginal bleeding disturbances. Women's views and experiences of their vaginal bleeding patterns: an international perspective from Norplant users. Eur J Contracept Reprod Health Care. 2011; 16:9-17.

57. Makuch MY, Duarte-Osis MJ, de Pádua KS, Petta C, Bahamondes L. Opinion and experience of Brazilian women regarding menstrual bleeding and use of combined oral contraceptives. Int J Gynecol Obstet. 2012;117:5-9.

58. Edelman A, Lew R, Cwiak C, Nichols M, Jensen J. Acceptability of contraceptiveinduced amenorrhea in a racially diverse group of US women. Contraception. 2007;75:450-3.
59. Lakehomer H, Kaplan PF, Wozniak DG, Minson CT. Characteristics of scheduled bleeding manipulation with combined hormonal contraception in university students. Contraception. 2013;88:426-30.

60. Wiegratz I, Hommel HH, Zimmermann T, Kuhl H. Attitude of German women and gynecologists towards long-cycle treatment with oral contraceptives. Contraception. 2004;69:37-42.

61. Andrist LC, Arias RD, Nucatola D, Kaunitz AM, Musselman BL, Reiter S, et al. Women's and providers' attitudes toward menstrual suppression with extended use of oral contraceptives. Contraception. 2004;70:359-63.

62. Andrist LC, Hoyt A, Weinstein D, McGibbon C. The need to bleed: women's attitudes and beliefs about menstrual suppression. J Am Acad Nurse Pract. 2004;16:31-7.

63. Bhatt $R$, Bhatt M. Perceptions of Indian women regarding menstruation. Int J Gynecol Obstet. 2005;88:164-7.

64. Ng QTK, Yuen PM. Preferred frequency of menstruation in Hong Kong Chinese women: characteristics and factors. Asia Pac J Public Health. 2008;20(Suppl):189-95.

65. Snow R, Hardy E, Kneuper E, Hebling EM, Hall G. Women's responses to menses and nonbleeding intervals in the USA, Brazil and Germany. Contraception. 2007;76:23-9.

66. Ferrero S, Abbamonte LH, Giordano M, Alessandri F, Anserini P, Remorgida V, et al. What is the desired menstrual frequency of women without menstruationrelated symptoms? Contraception. 2006;73:537-41.

67. Fruzzetti F, Paoletti AM, Lombardo M, Carmignani A, Genazzani AR. Attitudes of Italian women concerning suppression of menstruation with oral contraceptives. Eur J Contracept Reprod Health Care. 2008;13:153-7.

68. Marván ML, Lama C. Attitudes toward menstrual suppression and conformity to feminine norms in young and middle-aged Mexican women. J Psychosom Obstet Gynecol. 2009;30:147-55

69. Nappi RE, Fiala C, Chabbert-Buffet N, Häusler G, Jamin C, Lete I, et al. Women's preferences for menstrual bleeding frequency: results of the inconvenience due to Women's monthly bleeding (ISY) survey. Eur J Contracept Reprod Health Care. 2016;21:242-50.

70. Szarewski A, von Stenglin A, Rybowski S. Women's attitudes towards monthly bleeding: results of a global population-based survey. Eur J Contracept Reprod Health Care. 2012;17:270-83.

71. Nguyen LN, Jamieson MA. Adolescent users of an online contraception selection tool: how user preferences and characteristics differ from those of adults. J Pediatr Adolesc Gynecol. 2011;24:317-9.

72. Hooper DJ. Attitudes, awareness, compliance and preferences among hormonal contraception users: a global, cross-sectional, self-administered, online survey. Clin Drug Investig. 2010;30:749-63.

73. Hardy E, Hebling EM, de Sousa MH, Kneuper E, Snow R. Association between characteristics of current menses and preference for induced amenorrhea. Contraception. 2009;80:266-9.

74. Egarter C, Tirri BF, Bitzer J, Kaminskyy V, Oddens BJ, Prilepskaya V, et al. Women's perceptions and reasons for choosing the pill, patch, or ring in the CHOICE study: a cross-sectional survey of contraceptive method selection after counseling. BMC Womens Health. 2013;13:9.

75. Jensen JT, Nelson AL, Costales AC. Subject and clinician experience with the levonorgestrel-releasing intrauterine system. Contraception. 2008;77:22-9.

76. Adeyemi A, Adekanle D. Progestogen-only injectable contraceptive: experience of women in Osogbo, southwestern Nigeria. Ann Afr Med. 2012;11:27.

77. Arribas-Mir L, Rueda-Lozano D, Agrela-Cardona M, Cedeño-Benavides T, Olvera-Porcel C, Bueno-Cavanillas A. Insertion and 3-year follow-up experience of 372 etonogestrel subdermal contraceptive implants by family physicians in Granada, Spain. Contraception. 2009;80:457-62.

78. Barreiros FA, Guazzelli CAF, de Araújo FF, Barbosa R. Bleeding patterns of women using extended regimens of the contraceptive vaginal ring. Contraception. 2007;75:204-8.

79. Bastianelli C, Farris M, Benagiano G. Use of the levonorgestrel-releasing intrauterine system, quality of life and sexuality. Experience in an Italian family planning center. Contraception. 2011:84:402-8.

80. Blumenthal PD, Gemzell-Danielsson K, Marintcheva-Petrova M. Tolerability and clinical safety of Implanon ${ }^{\circledR}$. Eur J Contracept Reprod Health Care. 2008; 13:29-36.

81. Bortolotti de Mello Jacobucci MS, Guazzelli CAF, Barbieri M, Araújo FF, Moron AF. Bleeding patterns of adolescents using a combination contraceptive injection for 1 year. Contraception. 2006;73:594-7.

82. Bracken J, Graham CA. Young women's attitudes towards, and experiences of, long-acting reversible contraceptives. Eur J Contracept Reprod Health Care. 2014;19:276-84. 
83. Bradley JE, Alam M-E, Shabnam F, Beattie TSH. Blood, men and tears: keeping IUDs in place in Bangladesh. Cult Health Sex. 2009;11:543-58.

84. Canto de Cetina TE, Luna MO, Cetina Canto JA, Bassol S. Menstrual pattern and lipid profiles during use of medroxyprogesterone acetate and estradiol cypionate and NET-EN (200 mg) as contraceptive injections. Contraception. 2004:69:115-9.

85. Casey PM, Long ME, Marnach ML, Bury JE. Bleeding related to etonogestrel subdermal implant in a US population. Contraception. 2011;83:426-30.

86. Casey PM, Long ME, Marnach ML, Fleming-Harvey J, Drozdowicz LB, Weaver AL. Association of body mass index with removal of etonogestrel subdermal implant. Contraception. 2013:87:370-4.

87. Castle S. Factors influencing young Malians' reluctance to use hormonal contraceptives. Stud Fam Plan. 2003;34:186-99.

88. Cristobal I, Lete LI, de la VE, Perulero N, Arbat A, Canals I. One year quality of life measured with SEC-QoL in levonorgestrel 52mg IUS users. Contraception. 2016;93:367-71.

89. Darney P, Patel A, Rosen K, Shapiro LS, Kaunitz AM. Safety and efficacy of a single-rod etonogestrel implant (Implanon): results from 11 international clinical trials. Fertil Steril. 2009;91:1646-53.

90. Dickerson LM, Diaz VA, Jordon J, Davis E, Chirina S, Goddard JA, et al. Satisfaction, early removal, and side effects associated with long-acting reversible contraception. Fam Med. 2013;45:701-7.

91. Deokar AM, Jackson W, Omar HA. Menstrual bleeding patterns in adolescents using etonogestrel (ENG) implant. Int J Adolesc Med Health. 2011;23:75-7.

92. Diedrich JT, Desai S, Zhao Q, Secura G, Madden T, Peipert JF. Association of short-term bleeding and cramping patterns with long-acting reversible contraceptive method satisfaction. Am J Obstet Gynecol. 2015;212:50.e1-8.

93. Edelman A, Micks E, Gallo MF, Jensen JT, Grimes DA. Continuous or extended cycle vs. cyclic use of combined hormonal contraceptives for contraception. Cochrane Database Syst Rev. 2014. Issue 7. Art. No.: CD004695. https://doi.org/10.1002/14651858.CD004695.pub3.

94. Ezegwui HU, Ikeako LC, Ishiekwene CIC, Oguanua TC. The discontinuation rate and reasons for discontinuation of implanon at the family planning clinic of University of Nigeria Teaching Hospital (UNTH) Enugu, Nigeria. Niger J Med. 2011;20:448-50.

95. Flores JBO, Balderas ML, Bonilla MC, Vázquez-Estrada L. Clinical experience and acceptability of the etonogestrel subdermal contraceptive implant. Int J Gynaecol Obstet. 2005;90:228-33.

96. Harvey C, Seib C, Lucke J. Continuation rates and reasons for removal among Implanon ${ }^{\circledast}$ users accessing two family planning clinics in Queensland, Australia. Contraception. 2009;80:527-32.

97. Hoggart L, Newton VL, Dickson J. "I think it depends on the body, with mine it didn't work": explaining young women's contraceptive implant removal. Contraception. 2013;88:636-40.

98. Jeffreys LA, Clark AL. A successful approach to long-acting contraceptive implants in primary care. Contraception. 2012;85:381-3.

99. Jenabi E, Alizade SM, Baga RI. Continuation rates and reasons for discontinuing TCu380A IUD use in Tabriz, Iran. Contraception. 2006;74:483-6.

100. Lakha F, Glasier AF. Continuation rates of Implanon in the UK: data from an observational study in a clinical setting. Contraception. 2006;74:287-9.

101. Mansour D, Korver T, Marintcheva-Petrova M, Fraser IS. The effects of Implanon ${ }^{\circledast}$ on menstrual bleeding patterns. Eur J Contracept Reprod Health Care. 2008;13:13-28.

102. Mutihir JT, Nyango DD. Indications for removal of etonogestrel implant within two years of use in Jos, Nigeria. East Afr Med J. 2010;87:461-4.

103. Nanda K, Lendvay A, Kwok C, Tolley E, Dubé K, Brache V. Continuous compared with cyclic use of oral contraceptive pills in the Dominican Republic: a randomized controlled trial. Obstet Gynecol. 2014;123:1012-22.

104. Osei I, Birungi H, Addico G, Askew I, Gyapong JO. What happened to the IUD in Ghana? Afr J Reprod Health. 2005;9:76-91.

105. Riney S, O'Shea B, Forde A. Etonogestrel implant as a contraceptive choice; patient acceptability and adverse effect profile in a general practice setting. Ir Med J. 2009;102:24-5.

106. Rose SB, Cooper AJ, Baker NK, Lawton B. Attitudes toward long-acting reversible contraception among young women seeking abortion. J Women's Health 2002. 2011;20:1729-35.

107. Ruminjo JK, Sekadde-Kigondu CB, Karanja JG, Rivera R, Nasution M, Nutley T. Comparative acceptability of combined and progestin-only injectable contraceptives in Kenya. Contraception. 2005;72:138-45.

108. Sivin I, Croxatto H, Bahamondes L, Brache V, Alvarez F, Massai R, et al. Twoyear performance of a Nestorone ${ }^{\oplus}$-releasing contraceptive implant: a threecenter study of 300 women. Contraception. 2004;69:137-44.
109. Stephenson J, Shawe J, Panicker S, Brima N, Copas A, Sauer U, et al. Randomized trial of the effect of tailored versus standard use of the combined oral contraceptive pill on continuation rates at 1 year. Contraception. 2013;88:523-31.

110. Stoegerer-Hecher E, Kirchengast S, Huber JC, Hartmann B. Amenorrhea and BMI as independent determinants of patient satisfaction in LNG-IUD users: cross-sectional study in a central European district. Gynecol Endocrinol. 2012;28:119-24.

111. Sulak PJ, Kuehl TJ, Ortiz M, Shull BL. Acceptance of altering the standard 21day/7-day oral contraceptive regimen to delay menses and reduce hormone withdrawal symptoms. Am J Obstet Gynecol. 2002;186:1142-9.

112. Teal SB, Sheeder J. IUD use in adolescent mothers: retention, failure and reasons for discontinuation. Contraception. 2012;85:270-4.

113. Teunissen AM, Grimm B, Roumen FJME. Continuation rates of the subdermal contraceptive Implanon ${ }^{\circledR}$ and associated influencing factors. Eur J Contracept Reprod Health Care. 2014;19:15-21.

114. Thamkhantho M, Jivasak-Apimas S, Angsuwathana S, Chiravacharadej G, Intawong J. One-year assessment of women receiving sub-dermal contraceptive implant at Siriraj family planning clinic. J Med Assoc Thai. 2008;91:775-80.

115. Tolley E, Loza S, Kafafi L, Cummings S. The impact of menstrual side effects on contraceptive discontinuation: findings from a longitudinal study in Cairo, Egypt. Int Fam Plan Perspect. 2005;31:15-23.

116. Van Vliet HAAM, Grimes DA, Helmerhorst FM, Schulz KF, Lopez LM. Biphasic versus monophasic oral contraceptives for contraception. Cochrane Database Syst Rev. 2006. Issue 3. Art. No.: CD002032. https://doi.org/10. 1002/14651858.CD002032.pub2.

117. Van Vliet HAAM, Grimes DA, Lopez LM, Schulz KF, Helmerhorst FM. Triphasic versus monophasic oral contraceptives for contraception. Cochrane Database Syst Rev. 2011. Issue 11. Art. No.: CD003553. https://doi.org/10. 1002/14651858.CD003553.pub3.

118. Van Vliet HAAM, Raps M, Lopez LM, Helmerhorst FM. Quadriphasic versusmonophasic oral contraceptives for contraception. Cochrane Database Syst Rev. 2011. Issue 11. Art. No.: CD009038. https://doi.org/10. 1002/14651858.CD009038.pub2.

119. Van Vliet HAAM, Grimes DA, Helmerhorst FM, Schulz KF, Lopez LM. Biphasic versus triphasic oral contraceptives for contraception. Cochrane Database Syst Rev. 2006. Issue 3. Art. No.: CD003283. https://doi.org/10.1002/ 14651858.CD003283.pub2.

120. Weisberg E, Brache V, Alvarez F, Massai R, Mishell DR, Apter D, et al. Clinical performance and menstrual bleeding patterns with three dosage combinations of a Nestorone ${ }^{\circledast}$ progestogen/ethinyl estradiol contraceptive vaginal ring used on a bleeding-signaled regimen. Contraception. 2005;72:46-52.

121. Wong RC, Bell RJ, Thunuguntla K, McNamee K, Vollenhoven B. Implanon users are less likely to be satisfied with their contraception after 6 months than IUD users. Contraception. 2009:80:452-6.

122. Wood K, Jewkes R. Blood blockages and scolding nurses: barriers to adolescent contraceptive use in South Africa. Reprod Health Matters. 2006:14:109-18.

123. Yildizbas B, Sahin HG, Kolusari A, Zeteroglu S, Kamacı M. Side effects and acceptability of Implanon ${ }^{\oplus}$ : a pilot study conducted in eastern Turkey. Eur J Contracept Reprod Health Care. 2007;12:248-52.

124. Modesto W, Bahamondes MV, Bahamondes L. A randomized clinical trial of the effect of intensive versus non-intensive counselling on discontinuation rates due to bleeding disturbances of three long-acting reversible contraceptives. Hum Reprod. 2014;29:1393-9.

125. Obijuru L, Bumpus $S$, Auinger $P$, Baldwin CD. Etonogestrel implants in adolescents: experience, satisfaction, and continuation. J Adolesc Health. 2016;58:284-9.

126. Archer DF, Jensen JT, Johnson JV, Borisute H, Grubb GS, Constantine GD. Evaluation of a continuous regimen of levonorgestrel/ethinyl estradiol: phase 3 study results. Contraception. 2006;74:439-45.

127. Anderson F, Hait H. A multicenter, randomized study of an extended cycle oral contraceptive. Contraception. 2003;68:89-96.

128. Apter D, Briggs P, Tuppurainen M, Grunert J, Lukkari-Lax E, Rybowski S, et al. A 12-month multicenter, randomized study comparing the levonorgestrel intrauterine system with the etonogestrel subdermal implant. Fertil Steril. 2016:106:151-157.e5.

129. Bahamondes L, Brache V, Meirik O, Ali M, Habib N, Landoulsi S, et al. A 3-year multicentre randomized controlled trial of etonogestrel- and levonorgestrel-releasing contraceptive implants, with non-randomized matched copper-intrauterine device controls. Hum Reprod. 2015;30: 2527-38. 
130. Diedrich JT, Madden T, Zhao Q, Peipert JF. Long-term utilization and continuation of intrauterine devices. Am J Obstet Gynecol. 2015;213:822. e1-6

131. Rowe P, Farley T, Peregoudov A, Piaggio G, Boccard S, Landoulsi S, et al. Safety and efficacy in parous women of a 52-mg levonorgestrel-medicated intrauterine device: a 7-year randomized comparative study with the TCu380A. Contraception. 2016;93:498-506.

132. Hubacher D, Masaba R, Manduku CK, Chen M, Veena V. The levonorgestrel intrauterine system: cohort study to assess satisfaction in a postpartum population in Kenya. Contraception. 2015;91:295-300.

133. Granzow K. The 'nonmenstrual woman' in the new millennium? Discourses on menstrual suppression in the first decade of extended cycle oral contraception use in Canada. Cult Health Sex. 2014;16:620-33.

134. Johnston-Robledo I, Ball M, Lauta K, Zekoll A. To bleed or not to bleed: young Women's attitudes toward menstrual suppression. Women Health. 2003:38:59-75

135. Repta R, Clarke LH. "Am I going to be natural or am I not?": Canadian Women's perceptions and experiences of menstrual suppression. Sex Roles. 2013;68:91-106.

136. Rose JG, Chrisler JC, Couture S. Young Women's attitudes toward continuous use of oral contraceptives: the effect of priming positive attitudes toward menstruation on women's willingness to suppress menstruation. Health Care Women Int. 2008;29:688-701.

137. Makuch MY, Osis MJD, Petta CA, de Pádua KS, Bahamondes L. Menstrual bleeding: perspective of Brazilian women. Contraception. 2011;84:622-7.

138. Sánchez-Borrego R, García-Calvo C. Spanish women's attitudes towards menstruation and use of a continuous, daily use hormonal combined contraceptive regimen. Contraception. 2008;77:114-7.

139. Gunson JS. "More natural but less normal": reconsidering medicalisation and agency through women's accounts of menstrual suppression. Soc Sci Med. 2010;71:1324-31.

140. Szarewski A, Moeller C. Women's perceptions about reducing the frequency of monthly bleeding: results from a multinational survey. Open Access J Contracept. 2013;2013:29-37.

141. Greig AJ, Palmer MA, Chepulis LM. Hormonal contraceptive practices in young Australian women ( $\leqslant 25$ years) and their possible impact on menstrual frequency and iron requirements. Sex Reprod Healthc. 2010;1:99-103.

142. Kuhlmann AS, Henry K, Wall LL. Menstrual hygiene Management in Resource-Poor Countries. Obstet Gynecol Surv. 2017:72:356-76.

143. Curtis KM, Jatlaoui TC, Tepper NK, et al. U.S. Selected Practice Recommendations for Contraceptive Use, 2016. MMWR Recomm Rep. 2016; 65:1-66.

144. World Health Organization, K4Health, editors. Family planning: a global handbook for providers: evidence-based guidance developed through worldwide collaboration. [Geneva]: Baltimore: World Health Organization, Department of Reproductive Health and Research; John Hopkins Bloomberg School of Public Health, Center for Communication programs, Knowledge for Health Project; 2011.

145. Backman T, Huhtala S, Luoto R, Tuominen J, Rauramo I, Koskenvuo M. Advance information improves user satisfaction with the levonorgestrel intrauterine system. Obstet Gynecol. 2002;99:608-13.

146. Higgins JA, Smith NK. The sexual acceptability of contraception: reviewing the literature and building a new concept. J Sex Res. 2016;53:417-56.

147. Jain A, Reichenback L, Ehsan I, Rob U. "Side effects affected my daily activities a lot": a qualitative exploration of the impact of contraceptive side effects in Bangladesh. Open Access J Contracept. 2017:8:45-52.

148. Belsey EM, Machin D, d'Arcangues C. The analysis of vaginal bleeding patterns induced by fertility regulating methods. Contraception. 1986:34:253-60.

149. Halpern V, Lopez LM, Grimes DA, Stockton LL, Gallo MF. Strategies to improve adherence and acceptability of hormonal methods of contraception. Cochrane Database of Syst Rev. 2013, Issue 10. Art. No.: CD004317. https://doi.org/10.1002/14651858.CD004317.pub4..

150. Villavicencio J, Allen R. Unscheduled bleeding and contraceptive choice: increasing satisfaction and continuation rates. Open Access J Contracept. 2016;7:43.

151. Darney PD, Stuart GS, Thomas MA, Cwiak C, Olariu A, Creinin MD. Amenorrhea rates and predictors during 1 year of levonorgestrel $52 \mathrm{mg}$ intrauterine system use. Contraception. 2018;97:210-14

152. Abdel-AleemH, d'Arcangues C, Vogelsong KM, Gaffield ML, Gülmezoglu AM. Treatment of vaginal bleeding irregularities induced by progestin only contraceptives. Cochrane Database Syst Rev. 2013. Issue 10. Art. No: CD003449. https://doi.org/10.1002/14651858.CD003449.pub5.
153. Mansour D, Bahamondes L, Critchley H, Darney P, Fraser IS. The management of unacceptable bleeding patterns in etonogestrel-releasing contraceptive implant users. Contraception. 2011;83:202-10.

154. Weisberg E, Hickey M, Palmer D, O'Connor V, Salamonsen LA, Findlay JK, et al. A randomized controlled trial of treatment options for troublesome uterine bleeding in Implanon users. Hum Reprod. 2009;24:1852-61.

155. Friedlander E, Kaneshiro B. Therapeutic options for unscheduled bleeding associated with long-acting reversible contraception. Obstet Gynecol Clin N Am. 2015;42:593-603.

156. Rager KM, Fowler A, Omar HA. Successful treatment of depot medroxyprogesterone acetate-related vaginal bleeding improves continuation rates in adolescents. ScientificWorldJournal. 2006;6:353-5.

157. Sadeghi-Bazargani $H$, Ehdaeivand F, Arshi S, Eftekhar H, Sezavar H, Amanati L. Low-dose oral contraceptive to re-induce menstrual bleeding in amenorrheic women on DMPA treatment: a randomized clinical trial. Med Sci Monit. 2006;12:CR420-5.

158. Schelar E, Polis CB, Essam T, Looker KJ, Bruni L, Chrisman CJ, et al. Multipurpose prevention technologies for sexual and reproductive health: mapping global needs for introduction of new preventive products. Contraception. 2016;93:32-43.

159. Tolley EE, Morrow KM, Owen DH. Designing a multipurpose technology for acceptability and adherence. Antivir Res. 2013;100:S54-9.

160. Bahamondes L, Brache V, Meirik O, Ali M, Habib N, Landoulsi S. A 3-year multicentre randomized controlled trial of etonogestrel- and levonorgestrelreleasing contraceptive implants, with non-randomized matched copperintrauterine device controls. Hum Reprod. 2015;30:2527-38.

\section{Ready to submit your research? Choose BMC and benefit from:}

- fast, convenient online submission

- thorough peer review by experienced researchers in your field

- rapid publication on acceptance

- support for research data, including large and complex data types

- gold Open Access which fosters wider collaboration and increased citations

- maximum visibility for your research: over $100 \mathrm{M}$ website views per year

At BMC, research is always in progress.

Learn more biomedcentral.com/submissions 